\title{
Relationship among Depression, Anxiety and Mother-Infant Bonding in Mothers of Premature Babies
}

\author{
Zeinab Ahmed Mokhtar Abdelsalam ${ }^{1 *}$ \\ ${ }^{1}$ Lecturer of Psychiatric Mental Health Nursing, Faculty of Nursing, Cairo University
}

Received:June 19, 2017; Accepted: : July 3, 2017; Published: July 7, 2017

*Corresponding author: : Zeinab Ahmed Mokhtar Abdelsalam, Lecturer of Psychiatric Mental Health Nursing, Faculty of Nursing, Cairo University. E-mail: abdelsalam_zizi@yahoo.com

\begin{abstract}
Preterm birth is a multi-problematic event and can greatly affect the mother psychological wellbeing. The aim of this study was to assess the relationship among depression, anxiety, and mother-infant bonding in mothers of premature babies. A descriptive correlational research design was utilized in this study. A convenient sample of sixty mothers was recruited in this study. The study was conducted at the Neonatal Intensive Care Unit (NICU), at El Manial University Hospital. Data for this study were collected using four tools including socio-demographic data sheet, Beck Depression Inventory, Beck Anxiety Inventory and Mother- Infant Bond Scale. The results of the current study showed that mothers with premature babies suffer from severe level of anxiety and have high negative attitude toward their babies. Also, the study revealed that there was no statistical significant relationship between mothers' depression, anxiety and their bond with their babies. However, there was statistically significant direct relationship between mothers' depression and anxiety. The study concluded that, having premature baby can affect the mother's psychological state. The study recommended that, mothers of premature babies are in great need for psychological support and guidance. It is crucial to follow-up those mothers during their premature babies' development.
\end{abstract}

Keywords: Prematurity, Anxiety, Depression, Mother- Infant Bonding

\section{Introduction}

Approximately ten percent of the infants are born prematurely which means that they are born before 37 completed weeks of gestation. In Egypt, about 123,131 premature babies are born yearly [24]. According to Gangi, et al., hospitalization of premature infant in Neonatal Intensive Care Unit (NICU) is inescapable most of the time which exerts many psychological stressors on both parents and can antagonistically disturb the family strength [9].

As indicated by Misund, Nerdrum, Braten, Pripp, and Diseth, prematurity is categorized to two types (premature babies who are less than 37 weeks and very premature babies who are less than 32 weeks) [15]. In NICU, baby care is a subject of significant distraction leaving here and there parental misery out of sight. In any case, the effect of an extremely preterm birth on the parental full of feeling state is of high worry, as it constitutes an unpleasant occasion that may prompt post-traumatic anxiety responses of the parents [9]. As parents have to cope with the fear of the infant's death, the immaturity of the child and the risk of possible severe handicaps. Besides, these worries continue for a considerable length of time or months after the birth, constituting an enduring traumatic occasion with potential re-injury encounters [20].

Moreover, the parents of preterm infants often lack psychological support after the hospital discharge of the baby, driving them to be at high danger of creating mental issue, for example, significant depressive issue, nervousness issue or posttraumatic anxiety issue [10]. Without a doubt, it has been shown in several studies that, mothers of preterm infants report more severe levels of depression and anxiety in the neonatal period than mothers of full-term infants [6].

The premature birth may affect the emotional state of the mothers more durably, as studies detailed diligent depressive indications and post-traumatic side effects one year after birth [20].

More generally, it has been shown that untreated perinatal anxiety has negatively affects maternal wellbeing. Studies have examined the effects of maternal depression on the interactive relationship and found links between depression and infant cognitive, emotional and developmental delay [20]. Therefore, the importance of the parents' role in the lives of preterm infants is now recognized.

Postnatal depression has been widely documented as a important risk factor for woman's health, baby's development and the quality of mother-infant connections, recent studies have underlined that postnatal depression is associated to infants' level of oxytocin, impairing the mother response to stress $[18,2]$.

The prevalence of maternal depression and anxiety in the postpartum period is about15-20\% [19]. Whenever undiscovered, postnatal anxiety and depression may have long haul impacts both on the mother and on the newborn child and writings indicate how both dejection and nervousness affect on the nature of mother-infant connections, which show up as less synchronous and facilitated than those of non-depressed or nonanxious mother-infant dyads [16]. 
Recently, an increasing number of studies have paying attention on the impact of prematurity on untimely- interactions between mother and baby, finding that preterm dyads encounter poorer and less synchronous associations than full-term ones [12]. For example, For instance, preterm babies show up as less dynamic and responsive amid the cooperation with their moms than full-term newborn children; this is due to their biological immaturity.

Literature on mother-child interactions in preterm dyads shows some irregularities [1,12]. There is a lack of data exploring the relationship among the quality of early interactions, maternal depression, anxiety, and the severity of prematurity. To our knowledge, few studies have partially investigated this relationship, finding that the quality of mother-preterm infant interactions could be impaired in specific ways both by the presence of maternal depression and by the severity of premature birth.

\section{Significance of the Study}

It was noted by the researcher that there is limited evidence in the Egyptian literature about the presence of mother anxiety and depression, especially among those with premature babies. Almost none of the Egyptian published researches focused on the association between the mother disturbed psychological state and the bond or interaction with her baby.

Having a premature baby can affect the whole family not just the mother, however; lack of available support and empowerment of those mothers may lead to negative reactions that might impact the baby's development and health progress.

Infant prematurity can have many adverse effects on mother's psychological health, and in return, the mother reaction toward her premature baby is very crucial to understand by health professionals specifically nurses. Nurses play an important role in preparing the mothers of premature baby in order to care for her constantly demanding baby. The current study will fill the gap of knowledge about psychological state of mothers with premature babies and how that might affect their bonding with their infants. This will help the nurses to act in an understandable manner to those mothers' needs and problems.

Moreover, this study will enhance the nurses' practice to help the mothers to be well equipped of how to manage the tremendous problems and needs of those premature babies.

\section{Aim of the Study}

The aim of the current study was to assess the relationship among anxiety, depression, and mother's infant bonding in mothers with premature babies.

\section{Research Questions}

The subsequent research questions were formulated to fulfill the purpose of present study:

1.What are the levels of mother's depression?

2.What are the levels of mother's anxiety?
3.What are the levels of mother- infant bonding?

4.What are the relationships between depression, anxiety and mother-infant bonding?

\section{Subjects and Methods \\ Research Design}

The current study design was descriptive correlational, meaning that researcher seek to describe the relationships among variables, without attempting to infer causal connections [7].

\section{Sample}

A convenient sample of 60 mothers was recruited in this study. The sample size was calculated using G-power version 3.3.1 with a power of $(\beta=1-.95)$ with significance level of .05 (two tails), and medium effect size of (0.3). The inclusion criteria included mothers between the ages of (19-40) years old. In this study, exclusion criteria includes; those mothers with history of any psychiatric disease and those who have previous experience of having premature baby.

\section{Setting}

The study was conducted at the Neonatal Intensive Care Unit (NICU), at El Manial University Hospital. The (NICU) is special care unit equipped with the needed facilities to support premature babies' health.

\section{Tools of Data Collection}

In the current the researcher used four research tools which are:

\section{I.Socio-demographic Data Sheet.}

This tool was developed by researcher and it includes mother's age, level of education, occupation, place of residence, income, and duration of marriage.

\section{II.Beck Depression Inventory (BDI) (1961)}

Beck Depression Inventory (BDI) is a 21-item, self-report rating inventory that measures characteristic attitudes and symptoms of depression [5]. The inventory is on 4-point ranging from $(0=$ the absence of the symptoms) to $(3=$ the symptom is highly present) the highest summation of the points obtained by each participants indicates high depression. The scoring ranges for BDI are (1-10) = these ups and downs are considered normal; $(11-16)=$ mild mood disturbance; $(17-20)$ borderline clinical depression; $(21-30)=$ moderate depression; $(31-40)=$ severe depression; and (over40) = extreme depression. Internal consistency for the BDI ranges from .73 to .92 with a mean of .86 [4]. The BDI demonstrates high internal consistency, with alpha coefficients of .86 and .81 for psychiatric and non-psychiatric populations respectively [3]. In the current study the Cronbach's alpha for $\mathrm{BDI}=.96$ which is considered high reliability. 


\section{III.Beck Anxiety Inventory (BAI) (1988)}

This inventory was created by Beck, Epstein, Brown, and Steer is a 21-question multiple-choice self-report inventory that is used for measuring the severity of anxiety in children and adults [3]. The questions used in this measure ask about common symptoms of anxiety that the subject has had during the past week (including the day you take it) (such as numbness and tingling, sweating not due to heat and fear of the worst happening).

The scale consists of 21 items, each describing a common symptom of anxiety. The respondent is asked to rate how much he or she has been bothered by each symptom over the past week on a 4-point scale ranging from 0 to 3 ; not at all = (0); mild = (1); moderate $=(2)$; and severe $=(3)$. The items are summed to obtain a total score that can range from 0 to 63 . Total score is calculated by finding the sum of 21 questions. The scoring ranges for BAI are $(0-21)=$ low anxiety; $(22-35)=$ moderate anxiety; 36 and above $=$ potentially concerning levels of anxiety. The Cronbach's alpha of this scale in the current study was ( $\mathrm{r}=.91)$ which is considered high reliability.

\section{Mother-Infant Bonding Questionnaire (MIBQ)}

This tool was developed by Kumar [13]. The scale is used to assess the mother attitude toward her infant. The scale consists of ten items with a four-point ( 1 = "not at all" to 4 = "very much") Likert scale. Higher scores indicate greater negative attitudes towards the child. The Cronbach's alpha for this scale was calculated for this tool in the current study and it was $(r=.69)$ which is considered acceptable level of reliability.

\section{Translation of the Tools}

The researcher used the Arabic versions of BDI and BAI but, the MIBS was translated into Arabic language, reviewed for the accuracy of translation and tested for content validity by three professors in psychiatric nursing, at Cairo University.

\section{Procedure}

After an official permission was granted, the purpose of the study to was explained to the responsible personnel by the researcher. The researcher introduced herself to the director of the hospital, the supervisor of the neonatal intensive care unit and administrative personnel to gain their help and support during the data collection; the data collection phase took one month from April till May, 2017.

Each mother was interviewed individually during the visiting time to her baby in the neonatal intensive care unit, after explaining the purpose of the interview and agreement of eligible mothers was taken to participate in this study. The mothers were allowed to express their feelings freely by using open-ended questions after every question in the questionnaires, and the responses of the mothers were also recorded, each mother was interviewed individually for about 30 to 45 minutes depending on certain circumstances such as the participant's level of education or depth of discussion.

\section{Pilot study}

The questionnaire was pretested on a sample equal to $10 \%$ of the total sample size that were not part of the main study. No further medications were done to the scale.

\section{Ethical Consideration}

An official permission was obtained from the director of NICU at El Manial University Hospital. The researcher approached eligible mothers and an oral permission was taken from them in order to participate in the study. Data confidentiality and mothers' privacy were assured. The collected data was given code numbers and kept by the researcher to keep subjects' anonymity.

\section{Statistical Analysis}

Data were analyzed using SPSS statistical package for social science version 22. Frequency and percentage were used for numerical data as well as mean, standard deviation, median, minimum and maximum. Numbers and percentages were used to describe qualitative data. In addition, correlation coefficient was used to describe association between variables in the same group. Correlation coefficient ( $\mathrm{r}$ ) of 0.5 was considered fair correlation, if more than 0.5 to 0.75 , it was considered good correlation, and if more than 0.75 , then it was considered as very good correlation [21]. Probability ( $p$ - value) less than 0.05 was considered significant and less than 0.001 considered as highly significant.

Figures 1,2 show that, $(43,5 \%)$ of mothers age was between 20-25 years, with a mean age of 27 years old, and (40\%) of the mother had secondary school education

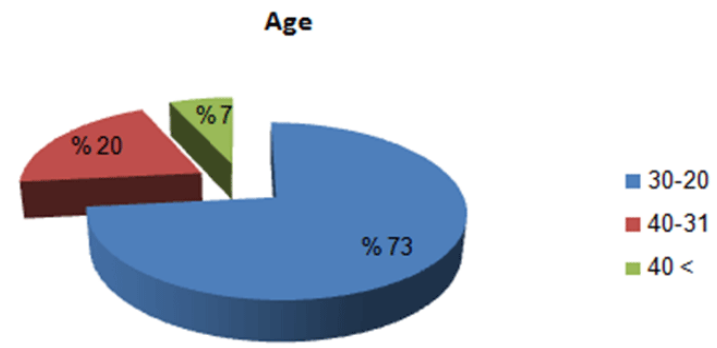

Figure 1: Frequency distribution of the studied sample according to their age categories $(n=30)$

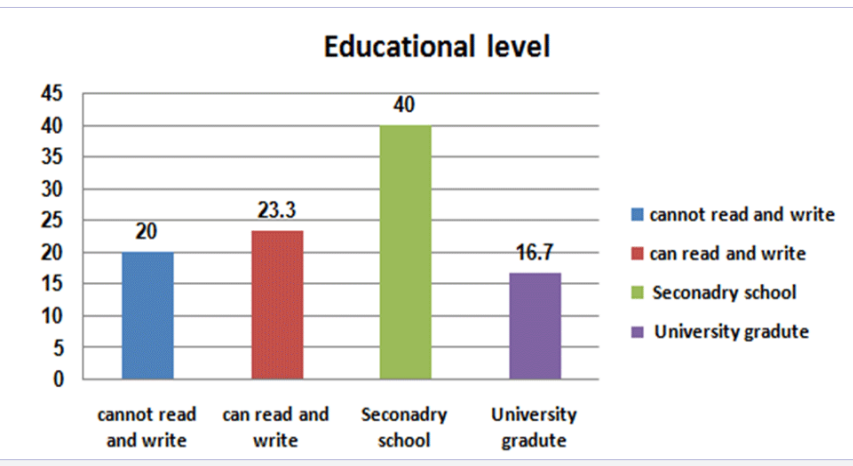

Figure 2: Frequency distribution of the studied sample according to their educational level $(n=30)$ 
Figures 3,4 indicate that (46.6) \% of the mother lives in urban area, and (96.7) \% of the mothers were not working.

The results show that $(66.6 \%)$ of the studied sample were complaining from physical symptoms while; (19.9\%) were complaining from psychological symptoms and (9.9\%) were complaining from social symptoms.

\section{Place of Residence}

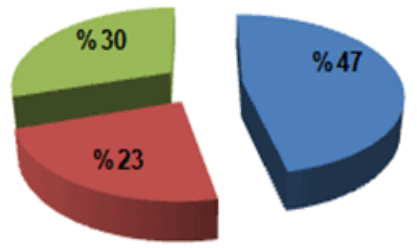

\section{urban \\ rural \\ in slyms}

Figure 3: Frequency distribution of the studied sample according to their place of residence $(n=30)$

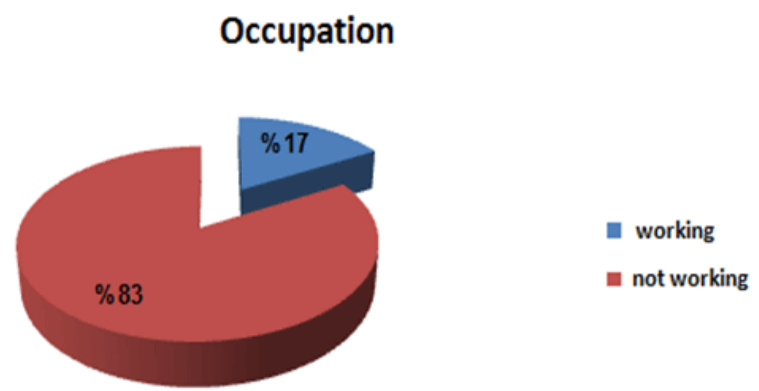

Figure 4: Frequency distribution of the studied sample according to their occupation $(n=30)$

Table 1 show that $(76.7 \%)$ of the studied sample had a duration of the sample less and equal to ten years while; $23.3 \%)$ of the studied sample had more than ten years duration of marriage.

\begin{tabular}{|c|c|c|}
\hline Duration of marriage & $\mathbf{N}$ & $\%$ \\
\hline$\leq 10$ years & 23 & 76.7 \\
\hline$>10$ years & 7 & 23.3 \\
\hline
\end{tabular}

Figure 5 shows that, $(36.7 \%)$ of the studied sample had minimal level of depression and $(26.7 \%)$ had moderate level of depression whereas; (3.3\%) had severe level of depression.

Figure 6 reveals that, $(36.7 \%)$ of the studied sample had severe level of anxiety and (26.7\%) had moderate level of anxiety whereas; (16.7\%) had minimal level of anxiety.

Figure 7 reveals that, $(83 \%)$ of the studied sample had high negative attitude toward their babies while, $(17 \%)$, had moderate negative attitude toward their babies.

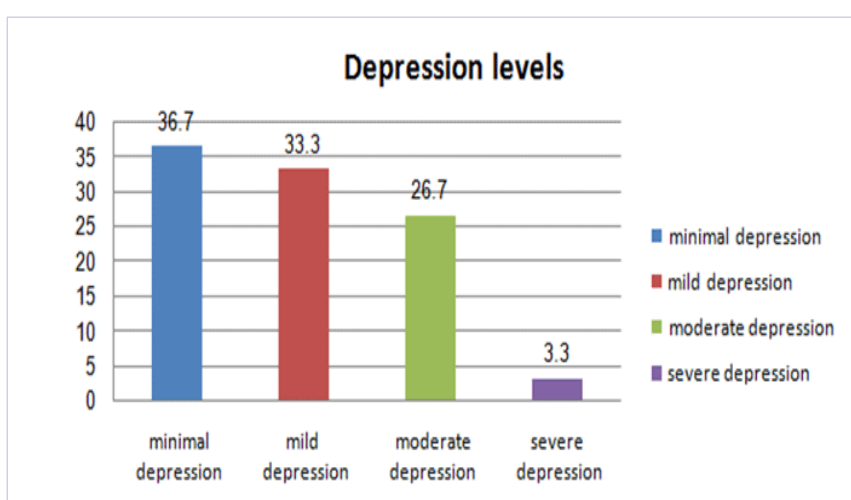

Figure 5: Frequency distribution of the studied sample according to depression levels $(n=30)$

\section{Anxiety levels}

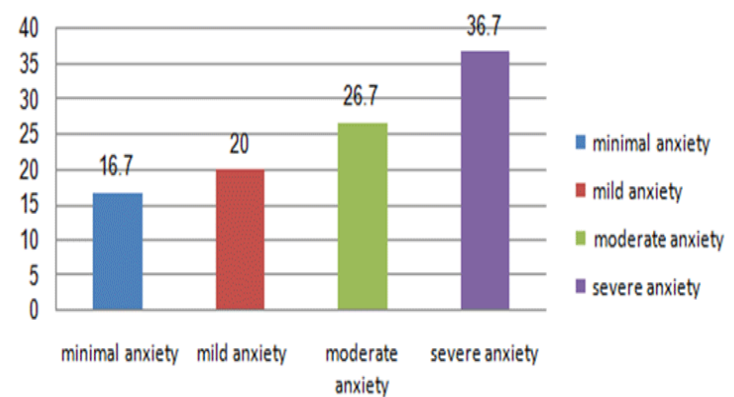

Figure 6: Frequency distribution of the studied sample according to anxiety levels $(n=30)$

Mother-infant bonding levels

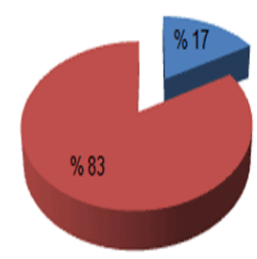

- moderate negative attitude

- high negative attitude

Figure 7: Frequency distribution of the studied sample according to mother-infant bonding levels ( $\mathrm{n}=30$ )

\section{Relationship among the Study Variables}

Table 2 reveals that, there were no statistical significant relationship among socio-demographic characteristics of the studied sample and totals of anxiety, depression, and mother-infant bonding. However, there was statistical relationship between mother's occupation and total depression scores as $(\mathrm{t}=2.284, \mathrm{p}=.030)$. 
Table 2: Relationship among socio-demographic characteristics of the studied sample and totals of anxiety, depression, and mother-infant bonding $(n=30)$

\begin{tabular}{|c|c|c|c|c|c|c|}
\hline & \multicolumn{2}{|c|}{ Depression scores } & \multicolumn{2}{|c|}{ Anxiety scores } & \multicolumn{2}{|c|}{ Anxiety scores } \\
\hline & F & $\mathrm{p}$ & $\mathrm{F}$ & $\mathrm{p}$ & F & $\mathrm{p}$ \\
\hline Age & .377 & .689 & .643 & .534 & .592 & .560 \\
\hline Educational level & 1.294 & .294 & .710 & .555 & 1.656 & .201 \\
\hline \multirow[t]{2}{*}{ Place of residence } & .750 & .482 & 1.478 & .264 & .780 & .468 \\
\hline & $\mathrm{t}$ & $\mathrm{p}$ & $\mathrm{t}$ & $\mathrm{p}$ & $\mathrm{t}$ & $\mathrm{p}$ \\
\hline Occupation & 2.284 & $.030^{*}$ & -.237 & .820 & 1.166 & .253 \\
\hline Income & .719 & .546 & -.839 & .412 & 1.273 & .227 \\
\hline
\end{tabular}

Table 3 shows that, there were statistically direct significant relationship between depression and anxiety, however, there were no statistically significant between depression, anxiety, and mother-infant bonding.

Table 3: Correlation matrix among depression, anxiety and motherinfant bonding among studied sample $(n=30)$

\begin{tabular}{|c|c|c|c|c|}
\hline \multirow{2}{*}{} & \multicolumn{2}{|c|}{ Anxiety score } & \multicolumn{2}{c|}{ Depressions score } \\
\cline { 2 - 5 } $\begin{array}{c}\text { Mother infant } \\
\text { bonding }\end{array}$ & $\mathbf{r}$ & $\mathbf{p}$ & $\mathbf{r}$ & $\mathbf{p}$ \\
\hline $\begin{array}{c}\text { Depression } \\
\text { score }\end{array}$ & .464 & 124 & -.200 & 290 \\
\hline *significant $p<0.05$ & & & \\
\hline
\end{tabular}

\section{Discussion}

The aim of the current study was to investigate the relationship among depression, anxiety and mother-infant bonging in mothers of premature babies. The findings showed that the majority of the studied sample was between the age group of $(20$ 30 ) years old and that is congruent with the findings of Petit, et al., Ionio, et al., Welch, et al., and Vazquez who found that their samples were in the same age group $[17,11,23,22]$.

Regarding the mothers' educational level, about less than half of the studied sample had secondary school education. This result is in the same line with [17]. On the other hand, this finding is dissimilar to the findings of Ionio, et al. and Welch, et al. who found that the majority of their samples had more than high school education $[11,23]$. Education can play an important role in determining the mothers' adherence to healthy lifestyles which in return affect the progress of healthy pregnancy and can reduce the risk for having premature baby.

Concerning the mothers' working status, majority of the studied sample were not working. This finding is contradicting with Ionio, et al. and Vazquez who found that all of their samples were working full time jobs $[11,22]$. In the current study, the majority of the sample had secondary school education which might decreased the chance for those mothers to find appropriate jobs.

The current results revealed that the majority of the studied sample had minimal level of depression. This is in the opposite of Ionio, et al. who conducted a study to assess the impact of preterm birth on parental distress and found that mothers of preterm babies suffer from higher depression scores than mothers of full term babies [11]. This finding is congruent with Vazquez who reported that mothers of preterm babies showed more depressive symptoms than mothers of full term babies [22]. This finding might be explained by the social support provided by the families of the mothers as reported by them during the data collection. The mothers said that, their husbands are usually not present to provide any emotional and psychological support however; the mothers' parents and siblings are usually their providing them with all types of support.

Regarding the level of anxiety, the findings of the current study showed that the majority of the studied sample was suffering from severe level of anxiety. This finding is in the same line with Ionio, et al., Malakouti, Jebraeili, Valizadeh, and Babapour who reported that mothers of premature babies suffer from high levels of anxiety immediately after the baby birth when compared to mothers of full term babies $[11,14]$. That high level of anxiety might be related to the vagueness that surrounds that baby's future. The mother usually is not fully aware of what will happen to her baby, will she/he continue or not and will she/ he will be normal as other babies or not. All are questions that the mother usually facing in silence, causing her to be more anxious than mothers of full term babies. Many research studies have proven that the premature birth may affect the emotional state of the mothers more durably, for example; Schneider and Colleagues have reported that persistent depressive symptoms and post-traumatic symptoms one year after birth [20].

Also, the results showed that the majority of the sample had negative attitudes toward their premature babies. This finding might be related to lack of knowledge about the needs and the problems of those babies. Those mothers reported to the researcher that they are afraid of the needs and the problems of their babies when discharged from the hospital. And it was notes that the medical team in the ICU do not allow the mothers to be physically close to their babies as it is recommended by the literature, because they afraid of infection transmission.

Although, the medical staff has the right to be concerned about the infection, however; lack of physical closeness as reported by Flacking, et al. who reported it is very crucial for mothers to phys- 
ical close to their babies during their stay at the ICUs to facilitate the mother-infant bonding [8]. This finding is in the same line with Korja, Latva and Lehtonen who reported in their systematic review that thirteen studies showed that mothers of preterm babies have more poor attachment to their babies as compared to mothers of full term babies [12]. On the other hand, Korja, Latva and Lehtonen revealed that five studies showed that mothers of preterm babies showed equal caring attitude and attachments as mothers of full term babies [12].

The current findings indicated that there were no statistical relationship between depression, anxiety, and mother-infant bonding. This finding is dissimilar with Ionio, et al., Vazquez who reported that there were significant correlations between mother's depression and mother-infant bonding. One of the reasons that might explain the insignificant correlations among the main study variable; is the fact of that they suffer from minimal level of depression which might affect the presence of relationship among those variables [11,22]. However, it was surprising to find no correlation between anxiety and mother-infant bonding. Which shade light to the idea that a follow-up to mothers might show a strong correlation between their anxiety and their bonding with their babies. Korja, Latva and Lehtonen reported that studies that followed-up those mothers during the first six months of their babies lives; showed a high level of distress and anxiety and low mother-infant attachment [12].

\section{Conclusion}

The present study concluded that mothers with premature babies suffer from severe level of anxiety and minimal level of depression. Although there were no relationships among mothers' anxiety, depression and their boning with their babies, those mothers showed high negative attitude toward their babies which affect their interactions with their babies.

\section{Recommendations}

-Based upon the findings of this study, the following recommendations are made:

-Early provision of psychological support to mothers of premature babies can help in reducing the vulnerability of having depression and anxiety.

-Implementation of educational nursing programs to nurses to equip them with the needed knowledge of how to manage the needs and the problems of mothers of premature babies.

-Nurses should be trained to identify mothers at risk to develop depression and anxiety as this will affect the mothers' quality of care provided to her babies.

-There should be available centers that can provide psychological support of mothers when premature babies discharge from the hospital.

- Raise the fathers and family members' awareness about the psychological needs of mothers of premature babies.

-The bio-psychosocial needs of mothers of premature babies should be more incorporated in the nursing curricula. -It will be interesting to investigate the father's level of depression and anxiety in different research studies.

- Further research studies are needed to be conducted with larger sample size and from different geographical areas around Egypt

\section{References}

1. Agostini F, Neri E, Salvatori P, Dellabartola S, Bozicevic L, Monti F. Antenatal depressive symptoms associated with specific life events and sources of social support among Italian women. Matern Child Health J. 2015;19(5):1131-1141. doi: 10.1007/s10995-014-1613-x

2. Apter-Levy Y, Feldman M, Vakart A, Ebstein RP, Feldman R. Impact of maternal depression across the first 6 years of life on the child's mental health, social engagement, and empathy: The moderating role of oxytocin. Am J Psychiatry. 2013;170(10):1161-1168. doi: 10.1176/ appi.ajp.2013.12121597

3. Beck AT, Epstein N, Brown G, Steer RA. An inventory for measuring clinical anxiety: psychometric properties. J Consult Clin Psychol. 1988;56(6):893-897.

4. Beck AT, Steer RA, Garbin MG. Psychometric properties of the Beck Depression Inventory: Twenty-five years of evaluation. Clinical Psychology Review. 1988;8(1):77-100.

5. Beck At, Ward Ch, Mendelson M, Mock J, Erbaugh J. An inventory for measuring depression. Arch Gen Psychiatry. 1961;4:561-571.

6. Brown HK, Speechley KN, Macnab J, Natale R, Campbell MK. Mild prematurity, proximal social processes, and development. Pediatrics. 2014;134(3).

7. Burns N, Grove SK. Understanding Nursing Research. 5th ed. Maryland Heights: Elsevier. 2010.

8. Flacking R, Lehtonen L, Thomson G, Axelin A, Ahlqvist S, Moran VH, et al. Closeness and separation in neonatal intensive care. Acta Paediatr. 2012;101(10):1032-1037. doi: 10.1111/j.1651-2227.2012.02787

9. Gangi S, Dente D, Bacchio E, Giampietro S, Terrin G, De Curtis M. Posttraumatic stress disorder in parents of premature birth neonates. Procedia- Social and Behavioral Sciences. 2013;82:882-885. doi: 10.1016/j.sbspro.2013.06.365

10. Huhtala M, Korja R, Lehtonen L, Haataja L, Lapinleimu H, Rautava P. Associations between parental psychological well-being and socioemotional development in 5-year-old preterm children. Early Hum Dev. 2014;90(3):119-124. doi: 10.1016/j.earlhumdev.2013.12.009

11. Ionio C, Colombo C, Brazzoduro V, Mascheroni E, Confalonieri E, Castoldi F. Mothers and Fathers in NICU: The Impact of Preterm Birth on Parental Distress. Eur J Psychol. 2016;12(4):604-621. doi: 10.5964/ ejop.v12i4.1093

12. Korja R, Latva R, Lehtonen L. The effects of preterm birth on motherinfant interaction and attachment during the infant's first two years. Acta Obstet Gynecol Scand. 2012;91(2):164-173. doi: 10.1111/j.16000412.2011 .01304

13. Kumar RC. "Anybody's child": severe disorders of mother-to-infant bonding. Br J Psychiatry. 1997;171:175-181.

14. Malakouti J, Jebraeili M, Valizadeh S, Babapour J. Mothers' experience of having a preterm infant in the neonatal intensive care unit, a phenomenological study. Iranian Journal of Critical Care Nursing. 
2013;5(4):172-181.

15. Misund AR, Nerdrum P, Bråten S, Pripp AH, Diseth TH. Long-term risk of mental health problems in women experiencing preterm birth: a longitudinal study of 29 mothers. Ann Gen Psychiatry. 2013;12(1):33. doi: 10.1186/1744-859X-12-33

16. Murray L, Arteche A, Fearon P, Halligan S, Goodyer I, Cooper P. Maternal postnatal depression and the development of depression in offspring up to 16 years of age. J Am Acad Child Adolesc Psychiatry. 2011;50(5):460-470. doi: 10.1016/j.jaac.2011.02.001

17. Petit AC, Eutrope J, Thierry A, Bednarek N, Aupetit L, Saad S, et al. Mother's Emotional and Posttraumatic Reactions after a Preterm Birth: The Mother-Infant Interaction Is at Stake 12 Months after Birth. PLoS One. 2016;11(3):e0151091. doi: 10.1371/journal.pone.0151091

18. Pratt M, Apter-Levi Y, Vakart A, Feldman M, Fishman R, Feldman T, et al. Maternal Depression And Child Oxytocin Response; Moderation By Maternal Oxytocin And Relational Behavior. Depress Anxiety. 2015;32(9):635-646. doi: 10.1002/da.22392
19. Rogers CE, Kidokoro $H$, Wallendorf $M$, Inder TE. Identifying mothers of very preterm infants at-risk for postpartum depression and anxiety before discharge. J Perinatol. 2013;33(3):171-176. doi: 10.1038/ jp.2012.75

20. Schneider LA, Burns NR, Giles LC, Higgins RD, Nettelbeck TJ, Ridding $\mathrm{MC}$, et al. Cognitive abilities in preterm and term-born adolescents. J Pediatr. 2014;165(1):170-177. doi: 10.1016/j.jpeds.2014.03.030

21. Shafer D, Zhang, Z. Beginning statistics. 2012.

22.Vazquez V. Relationships of Parent-Infant Contacts and Postpartum Depressive Symptoms in Mothers of Preterm Infants in the NICU: A Mixed Methods Approach. Doctoral Dissertations. 2015:965.

23. Welch MG, Halperin MS, Austin J, Stark RI, Hofer MA, Hane AA, et al. Depression and anxiety symptoms of mothers of preterm infants are decreased at 4 months corrected age with Family Nurture Intervention in the NICU. Arch Womens Ment Health. 2016;19(1):51-61. doi: 10.1007/s00737-015-0502-7

24. World Health Organization [WHO]. Born Too Soon: The Global Action Report on Preterm Birth. Geneva: World Health Organization. 2012. 